Григорьев И.В

\title{
ПРОБЕЛЫ И КОЛЛИЗИИ ЗАКОНОДАТЕЛЬСТВА О ПРОТИВОДЕЙСТВИИ КОРРУПЦИИ НА ГОСУДАРСТВЕННОЙ ГРАЖДАНСКОЙ СЛУЖБЕ РОССИЙСКОЙ ФЕДЕРАЦИИ
}

\begin{abstract}
Аннотация: В статье рассмотрены особенности правового регулирования противодействия коррупии на государственной гражданской службе Российской Федерации. Дается авторский анализ основных проблем, связанных с представлением государственными гражданскими служащими сведений о доходах, расходах, имуществе и обязательствах имущественного характера, а также с проведением проверки указанных сведений. Проанализированы отдельные элементы правового положения (статуса) гражданских служащих, носящие антикоррупционный характер. Выделены проблемы связанные с возможностью привлечения государственных гражданских служащих к дисциплинарной ответственности за совершение «коррупиионных правонарушений». Методологической основой работы послужили общенаучные методы системного анализа и обобщения нормативных, научных и практических материалов; частнонаучные методы - сравнительного правоведения, технико-юридический и др. Новизна статьи определяется тем, что она представляет собой комплексное исследование правовых вопросов противодействия коррупции на государственной гражданской службе Российской Федерации. К числу наиболее значимых результатов следует отнести сформулированные предложения по совершенствованию действующего гражданского законодательства и законодательства о государственной гражданской службе, а также сложившейся правоприменительной практики.
\end{abstract}

Ключевые слова: Государственная гражданская служба, противодействие коррупции, ответственность государственных служащих, сведения о доходах, сведения о расходах, подарок, конфликта интересов, счет, акиия, правовое положение (статус).

Abstract: This article explores the peculiarities of the legal regulation of anticorruption measures in the state civil service of the Russian Federation. The author analyzes the key issues in civil servants reporting income, expenses, property, as well as verification of these reports. Analysis is conducted on separate element of the legal status of civil servants that carry anticorruption character. The author highlights the issues pertaining to the possibility of bringing civil servants to disciplinary accountability for violations of corruption nature. The novelty of this research consists in the fact that in represents a comprehensive research of the legal issues of anticorruption measures in state civil service of the Russian Federation. The author formulates a proposal to improve the current civil legislation and legislation on state civil service.

Keywords: Account, conflict of interest, gift, expense reporting, income reporting, liability of public servants, anticorruption, civil service, stocks, legal status.

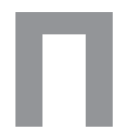
роблемы противодействия коррупции далеко не новы для российского государства. Со стороны высшего руководства страны неоднократно подчеркивалось, что низкая эффективность государственной власти и коррупция является очевидной и главной проблемой и принципиальной задачей была и остается борьба с коррупцией [1]. Предлагаемые Президентом РФ пути и механизмы противодействия коррупции, нашли законодательное закрепление в нормах, регламентирующих государственную гражданскую службу, касающихся отстранения от замещаемой должности и временный запрет на повторное замещение должностей; ограничения прав служащих иметь зарубежные счета, ценные бумаги иностранных организаций, недвижимость за пределами территории РФ и др. Вместе с тем нужно признать, что отдельные положения законодательства о противодействии коррупции носят несовершенный [2] и противоречивый характер.

Начнем с правового регулирования предоставления служащими сведений о доходах, имуществе и обязательствах имущественного характера. Ежегодно служащий должен отчитаться не только о своих доходах (расходах), но и о доходах (расходах) своего супруга(и) и несовершеннолетних детей (кроме случаев невозможности представления доходов супругов и детей по объективным и уважительным причинам). Здесь есть целый ряд проблем: 
1) единственный документ, определяющий объективность и уважительность причин непредставления вышеназванных сведений - это Письмо Министерства труда и социальной защиты РФ от 18 июля 2013 № 18-2/10/2-4038 «Разъяснения по применению Федерального закона от 3 декабря 2012 г. № 230-Ф3 «О контроле за соответствием расходов лиц, замещающих государственные должности, и иных лиц их доходам» и иных нормативных правовых актов в сфере противодействия коррупции» (вместе с «Разъяснениями по применению Федерального закона от 3 декабря 2012 г. № 230-Ф3 «О контроле за соответствием расходов лиц, замещающих государственные должности, и иных лиц их доходам» и иных нормативных правовых актов в сфере противодействия коррупции» (законодательство по состоянию на 17 июля 2013 г.)» [3]), в котором называются ряд таких причин: а) супруги при юридически оформленном браке фактически не проживают друг с другом и (или) б) между ними существуют личные неприязненные отношения, в) супруг (супруга) признан безвестно отсутствующим, г) находится в розыске и т.д.. То есть перечень является открытым. Вопрос об объективности и уважительности причин должен решаться комиссией по соблюдению требований к служебному поведению и урегулированию конфликта интересов в каждом конкретном случае, однако практика деятельности комиссий показывает, что названный перечень практически всегда рассматривается как исчерпывающий. При этом не ясно, как комиссия должна оценивать объяснения служащих: у нее нет возможности проверить проживают супруги вместе или нет, а документально подтвердить это невозможно.

Государственные служащие обязаны представить сведения о доходах супруга(и), но ни в одном акте не закреплена обязанность супруга предоставить супругу-служащему сведения о своих доходах. Для устранения данной проблемы необходимо на супругов гражданских служащих нормативно возложить обязанность по представлению сведений о своих доходах, имуществе и обязательствах имущественного характера. Более того, необходимо изменить сложившуюся практику, в том числе судебную, привлечения служащих к ответственности без их вины. Например, в Апелляционном определении Судебной коллегии по гражданским делам Курганского областного суда по Делу № 33-6/2015 (33-3767/2014;) указано, что если супруга служащего скрыла от него свой действительный доход и отказала в запросе у работодателя справок о доходах - то это касается межличностных отношений супругов и не освобождает служащего от исполнения обязанностей, возложенных на него как на государственного гражданского служащего [4]. Судами не учитывается, что государственные гражданские служащие, предоставляя неточные сведения, полученные от супругов, не имеют самостоятельной возможности проверить их полноту и достоверность. При этом следует отметить, что увольнение в связи с утратой доверия (относительно новое основание увольнения, применяемое за «коррупционные правонарушения» [5]) встречается достаточно редко: за три квартала 2015 года было выявлено более 20 тысяч коррупционных правонарушений, разбирательства по которым привели к увольнению 340 служащих - в связи с утратой доверия, а 176 - в связи с конфликтом интересов [6].

2) Правоприменители зачастую проводят проверку сведений, представленных всеми служащими, в то время как основания для проведения проверки достоверности полноты представленных сведений о доходах четко определены в указе Президента РФ от 21.09.2009 № 1065 (ред. от 15.07.2015) «О проверке достоверности и полноты сведений, представляемых гражданами, претендующими на замещение должностей федеральной государственной службы, и федеральными государственными служащими, и соблюдения федеральными государственными служащими требований к служебному поведению» [7]: по которому «основанием для осуществления проверки является достаточная информация, представленная в письменном виде в установленном порядке: а) правоохранительными органами, иными государственными органами, органами местного самоуправления и их должностными лицами; а.1) работниками подразделений кадровых служб федеральных государственных органов по профилактике коррупционных и иных правонарушений либо должностными лицами кадровых служб указанных органов, ответственными за работу по профилактике коррупционных и иных правонарушений; б) постоянно действующими руководящими органами политических партий и зарегистрированных в соответствии с законом иных общероссийских общественных объединений, не являющихся политическими партиями; в) Общественной палатой Российской Федерации; г) общероссийскими средствами массовой информации». При отсутствии соот- 


\section{Право и политика $10(202) \cdot 2016$}

ветствующих обращений проведение проверок является необоснованным.

3) Говоря об ответственности государственных гражданских служащих за непредставление сведений о доходах, имуществе и обязательствах имущественного характера нужно отметить, что статьи 16 и 20 Федерального закона от 27.07.2004 № 79-Ф3 (ред. от 30.06.2016) «О государственной гражданской службе РФ» [8] называют это «случаем, при котором гражданский служащий не может находиться на гражданской службе» или «правонарушением, влекущим увольнение гражданского служащего с гражданской службы», а ст. 59.3 , регламентирующая порядок привлечения к ответственности за коррупционные правонарушения обязывает представителя нанимателя учесть: характер совершенного гражданским служащим коррупционного правонарушения, его тяжесть, обстоятельства, при которых оно совершено, соблюдение гражданским служащим других ограничений и запретов, требований о предотвращении или об урегулировании конфликта интересов и исполнение им обязанностей, установленных в целях противодействия коррупции, а также предшествующие результаты исполнения гражданским служащим своих должностных обязанностей. Учитывая вышеназванные обстоятельства представитель нанимателя не имеет практической возможности уволить служащего впервые непредставившего сведения (представившего недостоверные или неполные сведения) и не имеющего других взысканий (вышеуказанные данные о числе уволенных подтверждают данный вывод).

Проблемы возникают и с применением статей 59.1. и 59.2 Федерального закона от «О государственной гражданской службе РФ», регламентирующих виды взысканий за «коррупционные правонарушения». Статья 59.1 устанавливает, что за несоблюдение служащим ограничений и запретов, требований о предотвращении или об урегулировании конфликта интересов и неисполнение обязанностей, установленных в целях противодействия коррупции настоящим Федеральным законом, Федеральным законом от 25 декабря 2008 года 273-Ф3 (ред. ред. от 15.02.2016) «О противодействии коррупции» [9] (далее - Закон № 273-ФЗ) и другими федеральными законами, налагаются следующие взыскания: а) замечание; б) выговор; в) предупреждение о неполном должностном соответствии. Статья 59.2 расширяет список случаев наступления ответственности за неисполнение ряда обязанностей, предусмотренных Законом №
273-Ф3, указывая, что гражданский служащий подлежит увольнению в связи с утратой доверия в случаях: а) непринятия служащим мер по предотвращению и (или) урегулированию конфликта интересов, стороной которого он является; б) непредставления гражданским служащим сведений о своих доходах, расходах, об имуществе и обязательствах имущественного характера, а также о доходах, расходах, об имуществе и обязательствах имущественного характера своих супруги (супруга) и несовершеннолетних детей либо представления заведомо недостоверных или неполных сведений; в) участия гражданского служащего на платной основе в деятельности органа управления коммерческой организацией, за исключением случаев, установленных федеральным законом; г) осуществления гражданским служащим предпринимательской деятельности; д) вхождения гражданского служащего в состав органов управления, попечительских или наблюдательных советов, иных органов иностранных некоммерческих неправительственных организаций и действующих на территории РФ их структурных подразделений, если иное не предусмотрено международным договором РФ или законодательством РФ; е) нарушения гражданским служащим, его супругой (супругом) и несовершеннолетними детьми запрета открывать и иметь счета (вклады), хранить наличные денежные средства и ценности в иностранных банках, расположенных за пределами территории РФ, владеть и (или) пользоваться иностранными финансовыми инструментами. В такой ситуации статья 59.1 закона нуждается в уточнении «кроме случаев, предусмотренных статьей 59.2 настоящего Закона». Проведенный Министерством труда и социальной защиты РФ анализ практики государственных органов по привлечению служащих к ответственности показывает, что увольнение в связи с утратой доверия, применялись в случаях: a) сокрытия доходов, имущества, источники происхождения которых служащий не мог пояснить или стоимость которых не соответствовала его доходам; б) значительного завышения служащим общей суммы доходов, вкладов в банках и иных кредитных организациях, либо полученных кредитов с целью финансового обоснования сделок по приобретению земельных участков, объектов недвижимого имущества, транспортных средств, ценных бумаг; в) указания цены сделки по приобретению земельных участков, объектов недвижимого имущества, транспортных средств, ценных бумаг, существенно ниже рыночной, для создания 
видимости соответствия расходов доходам служащего; г) сокрытия факта наличия банковских счетов, движение денежных средств по которым в течение отчетного года не могло быть объяснено исходя из доходов служащего; д) сокрытия информации о фактах получения доходов от продажи имущества по цене существенно выше рыночной; е) сокрытия информации о фактах получения кредитов на льготных условиях от банков и иных кредитных организаций, в отношении которых служащий выполнял функции государственного (муниципального) управления [10].

Сроки привлечения государственных гражданских служащих к ответственности за коррупционные правонарушения определены статьей 59.3 Федерального закона «О государственной гражданской службе РФ», согласно которой взыскания налагаются не позднее одного месяца со дня поступления информации о совершенном служащим правонарушении. В указанный срок не засчитываются периоды, когда служащий отсутствовал на службе по уважительным причинам (болезнь, отпуск и др.), а также время проведения проверки и рассмотрения ее материалов комиссией по соблюдению требований к служебному поведению и урегулированию конфликта интересов. При этом взыскание должно быть наложено не позднее шести месяцев со дня поступления информации о совершении коррупционного правонарушения. Согласимся с учеными, утверждающими, что срок привлечения к ответственности за дисциплинарный проступок должен исчисляться со дня его обнаружения лицом, которому подчинен гражданский служащий, независимо от того, наделено ли оно правом наложения дисциплинарных взысканий [11], при привлечении к ответственности за коррупционное правонарушение должен применяться аналогичный подход. Отдельно отметим, что на сегодняшний день «срок давности» привлечения к дисциплинарной ответственности за «коррупционные правонарушения» (составляющий три года) определен не законом, а Положением «О проверке достоверности и полноты сведений, представляемых гражданами, претендующими на замещение должностей федеральной государственной службы, и федеральными государственными служащими, и соблюдения федеральными государственными служащими требований к служебному поведению», утв. указом Президента РФ от 21.09.2009 № 1065 (ред. от 15.07.2015) [12].

4) Не лишена недостатков и терминология законодательства о противодействии коррупции. В частности, термин «доход» имеет неоднозначное значение, что нередко приводит к нарушениям при решении вопросов о наличии или отсутствии нарушений в действиях гражданского служащего. Необходимо согласиться с мнением Д.В. Осинцева, утверждающего, что «доходом» может быть признана только экономическая выгода» [13]. Поэтому формально не следует считать доходом получение служащим любых денежных средств (в том числе от реализации имущества ниже цены, за которую оно было приобретено).

5) Трендом последнего времени стал контроль за расходами служащих и членов их семей. С 2013 года служащим, помимо сведений о доходах необходимо представить сведения о расходах, если сумма сделки превышает общий доход служащего и его супруги (супруга) за три последних года, предшествующих совершению сделки. Данную меру нельзя признать эффективной, поскольку служащий (его супруг(a)) имеют возможность представить документы, подтверждающие сделку, которая, на самом, деле является мнимой (например, в подтверждение договора займа и его условий может быть представлена расписка заемщика или иной документ, удостоверяющие передачу ему займодавцем определенной денежной суммы или определенного количества вещей. Служащий может представить копию расписки на любую сумму, в то время как ее оригинал - уничтожить).

Анализ норм Федерального закона «О государственной гражданской службе РФ» определяющих правовое положение (статус) гражданских служащих позволяет выделить ряд, носящих антикоррупционную направленность, которые не лишены недостатков:

1) Следует отметить, что гражданскому служащему разрешается иметь в собственности ценные бумаги, акции (доли участия, паи в уставных (складочных) капиталах организаций), несмотря на то, что положения о владении закреплены в статье о запретах, связанных со службой. Нормативно определяется, что только в случае, если владение гражданским служащим ценными бумагами, акциями (долями участия, паями в уставных (складочных) капиталах организаций) приводит или может привести к конфликту интересов, гражданский служащий обязан передать принадлежащие ему ценные бумаги, акции (доли участия, паи в уставных (складочных) капиталах организаций) в доверительное управление. Фактически, служащим, владеющим ценными бумагами, настоятельно 


\section{Право и политика $10(202) \cdot 2016$}

рекомендуется от них избавиться, что нельзя признать неправомерным.

2) Отдельно необходимо рассмотреть вопрос, связанный с подарками государственным гражданским служащим [14]. Проблема заключается в несовершенстве правового регулирования данного института, поскольку Гражданский кодекс РФ разрешает получать подарки, а Федеральный закон «О гражданской службе РФ»-запрещает. Так статья 575 Гражданского кодекса РФ устанавливает, что запрещается дарение, за исключением обычных подарков (стоимость которых превышает трех тысяч рублей) государственным служащим... в связи с их должностным положением или в связи с исполнением ими служебных обязанностей. Данный запрет не распространяется на случаи дарения в связи с протокольными мероприятиями, служебными командировками и другими официальными мероприятиями. Подарки, которые получены государственными служащими, и стоимость которых превышает три тысячи рублей, признаются соответственно федеральной собственностью, собственностью субъекта Российской Федерации и передаются служащим по акту в орган, в котором указанное лицо замещает должность.

В статье 17 Федерального закон «О государственной гражданской службе РФ» говорится о двух видах подарков: а) подарки (денежное вознаграждение, ссуды, услуги, оплату развлечений, отдыха, транспортных расходов и иные вознаграждения) от физических или юридических лиц, получать которые запрещено (получение вознаграждений от физических и юридических лиц является весьма распространенным коррупционным правонарушением, имеющее наибольшую степень латентности [15]) и б) подарки, полученные гражданским служащим в связи с протокольными мероприятиями, со служебными командировками и с другими официальными мероприятиями, признаются соответственно федеральной собственностью и собственностью субъекта РФ и передаются гражданским служащим по акту в государственный орган, в котором он замещает должность, за исключением случаев, установленных Гражданским кодексом РФ. Считаем, что пп. 3 п. 2 ст. 575 Гражданского кодекса РФ, допускающий возможность получения подарков служащими необходимо признать утратившим силу.

Порядок оценки, сдачи и выкупа подарков, полученных служащими регламентируется на федеральном уровне постановлением Правительства от 9 января 2014 г. № 10 (ред. от 12.10.2015) «О порядке сообщения отдельными категориями лиц о получении подарка в связи с протокольными мероприятиями, служебными командировками и другими официальными мероприятиями, участие в которых связано с исполнением ими служебных (должностных) обязанностей, сдачи и оценки подарка, реализации (выкупа) и зачисления средств, вырученных от его реализации» (вместе с «Типовым положением о сообщении отдельными категориями лиц о получении подарка в связи с протокольными мероприятиями, служебными командировками и другими официальными мероприятиями, участие в которых связано с исполнением ими служебных (должностных) обязанностей, сдаче и оценке подарка, реализации (выкупе) и зачислении средств, вырученных от его реализации») [16] и представляется достаточно сложным, поскольку необходимо: в государственном органе необходимо образовать комиссию по поступлению и выбытию активов; определить стоимости подарка на основе рыночной цены, действующей на дату принятия к учету подарка, что производится, как правило, экспертным путем; предоставить возможность служащему выкупить подарок; решить вопрос о целесообразности использования подарка для обеспечения деятельности государственного органа; при необходимости принять меры по реализации подарка, его безвозмездной передаче на баланс благотворительной организации, либо о его уничтожении.

Закон № 273-Ф3 устанавливает, что порядок выкупа подарка, определяется нормативными правовыми актами Российской Федерации и в первоначальной редакции Типовое положение распространялось на лиц, замещающих государственные (муниципальные) должности, государственных (муниципальных) служащих, служащих Центрального банка РФ, работников Пенсионного фонда РФ, Фонда социального страхования РФ, Федерального фонда обязательного медицинского страхования, иных организаций, созданных Российской Федерацией на основании федеральных законов, а также организаций, созданных для выполнения задач, поставленных перед федеральными государственными органами. Однако действующее Типовое положение лишь рекомендовано к использованию при разработке и утверждении собственных порядков сообщения о получении подарка в связи с протокольными мероприятиями, служебными командировками и другими официальными мероприятиями, участие 
в которых связано с исполнением служебных (должностных) обязанностей, его сдачи, оценки и реализации (выкупа) федеральным государственным органам, органам государственной власти субъектов РФ и органам местного самоуправления, Центральному банку РФ и организациям, созданным Российской Федерацией на основании федеральных законов, организациям, созданным для выполнения задач, поставленных перед федеральными государственными органами.

В заключении хотелось бы отметить, что проблемы коррупции не решены ни в одной стране. И ужесточение мер ответственности не приведет к ее исчезновению, о чем свидетельствуют страны, в которых предусмотрена смертная казнь за совершение коррупционных преступлений. Считаем, что на сегодняшний день необходимо привести в соответствие имеющиеся нормативные правовые акты, устранить пробелы в правовом регулировании противодействия коррупции, а одним из основных средств противодействия коррупции должно стать воспитание у студентов «нетерпимости к коррупционному поведению», которое является одной из общекультурных компетенций, определенных государственными образовательными стандартами.

\section{Библиография:}

1. Послание Президента РФ Дмитрия Медведева Федеральному Собранию РФ от 30.11.2010 // Российская газета. 2010. 01 января № 271; Послание Президента РФ Владимира Путина Федеральному Собранию РФ от 03.12.2015 // Российская газета. 2015. 04 декабря. № 275.

2. Цалиев А.М. Конституционные (уставные) суды в механизме противодействия коррупции // Российская юстиция. 2016. № 7 (июль). С. 4.

3. Солидарность. $31.07-07.08 .2013$. № 27.

4. Официальный сайт Курганского областного суда: URL: https://oblsud--krg.sudrf.ru/modules.php?name=sud delo\&srv_num $=1 \&$ name_op=doc\&number=1544973\&delo_id=5\&new=5\&text_number=1\&case_id=1334877 (дата обращения: 18 сент. 2016 г.).

5. Выявление нарушений законодательства о противодействии коррупции средствами прокурорского надзора: методические рекомендации / [Т.Л. Козлов и др.]; Академия Генеральной прокуратуры Российской Федерации. М., 2012. С. 18-19.

6. Материалы заседания Совета при Президенте РФ по противодействию коррупции от 26 января 2016 года: URL: http://kremlin.ru/events/president/news/51207 (дата обращения 18 сент. 2016 г).

7. Собрание законодательства РФ. 2009. № 39. Ст. 4588.

8. Собрание законодательства РФ. 2004. № 31. Ст. 3215.

9. Собрание законодательства РФ. 2008. № 52 (ч. 1). Ст. 6228.

10. Письмо Министерства труда и социальной защиты РФ от 13 ноября 2015 г. № 18-2/10/П-7073 «Методические рекомендации по привлечению к ответственности государственных (муниципальных) служащих за несоблюдение ограничений и запретов, требований о предотвращении или об урегулировании конфликта интересов и неисполнение обязанностей, установленных в целях противодействия коррупции». Официальный сайт Министерства труда и социальной защиты РФ: URL: http://www.rosmintrud.ru/ministry/programms/gossluzhba/16/ antikorr/2/18 (дата обращения: 18 сент. 2016 г.)

11. Чаннов С. Проступок госслужащего: важен срок обнаружения. ЭЖ-Юрист. 2011. № 45 (Из информационного банка «Юридическая пресса») // КонсультантПлюс.

12. Собрание законодательства РФ. 2009. № 39. Ст. 4588.

13. Осинцев Д.В. Квалификация «доходов»в российском законодательстве о противодействии коррупции // Российский юридический журнал. 2014. № 1. С. 89.

14. По данным Министра труда и социальной защиты РФ в период с 1 января 2014 года по 30 июня 2016 года должностными лицами федеральных государственных органов, работниками их подведомственных организаций, государственных корпораций и фондов, а также служащими Банка России сдано 4650 подарков. Из них 1255 - чья стоимость составила менее трёх тысяч рублей - возвращены владельцам. Остальные выкуплены, переданы благотворительным организациям или сданы на хранение; 14 подарков, изготовленных из драгоценных металлов, направлены в Гохран России. Материалы заседания Президиума Совета при Президенте РФ по противодействию коррупции от 19 июля 2016 года: URL: http://kremlin.ru/events/administration/52540 (дата обращения 18 сент. 2016 г).

15. Выявление нарушений законодательства о противодействии коррупции средствами прокурорского надзора: методические рекомендации / [Т.Л. Козлов и др.]; Академия Генеральной прокуратуры Российской Федерации. М., 2012. С. 24.

16. Собрание законодательства РФ. 2014. № 3. Ст. 279.

17. Кабанов П.А. Правовые средства формирования и обеспечения реализации государственной политики противодействия коррупции в субъектах Российской Федерации: некоторые вопросы повышения качества // Юридические исследования. 2014. № 8. C. 36 - 47. DOI: 10.7256/2409-7136.2014.8.12004. URL: http://www.enotabene.ru/lr/article_12004.html 
DOI: $10.7256 / 1811-9018.2016 .10 .20314$

При цитировании этой статьи сноска на dоі обязательна

Право и политика $10(202) \cdot 2016$

18. Агеев В.Н. Ограничение прав и свобод муниципальных служащих как способ противодействия коррупции // Тренды и управление. 2013. № 3. С. 72-81. DOI: 10.7256/2307-9118.2013.3.7244.

\section{References (transliterated):}

1. Tsaliev A.M. Konstitutsionnye (ustavnye) sudy v mekhanizme protivodeistviya korruptsii // Rossiiskaya yustitsiya. 2016. № 7 (iyul'). S. 4.

2. Channov S. Prostupok gossluzhashchego: vazhen srok obnaruzheniya. EZh-Yurist. 2011. № 45 (Iz informatsionnogo banka «Yuridicheskaya pressa») // Konsul'tantPlyus.

3. Osintsev D.V. Kvalifikatsiya «dokhodov» v rossiiskom zakonodatel'stve o protivodeistvii korruptsii // Rossiiskii yuridicheskii zhurnal. 2014. № 1. S. 89.

4. Kabanov P.A. Pravovye sredstva formirovaniya i obespecheniya realizatsii gosudarstvennoi politiki protivodeistviya korruptsii v sub"'ektakh Rossiiskoi Federatsii: nekotorye voprosy povysheniya kachestva // Yuridicheskie issledovaniya. 2014. № 8. C. 36 - 47. DOI: 10.7256/2409-7136.2014.8.12004. URL: http://www.e-notabene.ru/lr/article 12004.html

5. Ageev V.N. Ogranichenie prav i svobod munitsipal'nykh sluzhashchikh kak sposob protivodeistviya korruptsii // Trendy i upravlenie. 2013. № 3. C. 72-81. DOI: 10.7256/2307-9118.2013.3.7244. 